\title{
Treatment Burden in People with Hypertension is Correlated with Patient Experience with Self- Management
}

\author{
Elizabeth A. Rogers, MD, MAS, Hani Abi, BA, Mark Linzer, MD, and \\ David T. Eton, PhD
}

Introduction: New hypertension guidelines in the United States may require more people to take multiple medications or implement lifestyle changes. Increased treatment burden may be an unintended consequence and lead to worse health outcomes. Our study examined whether treatment burden is associated with factors related to self-management in those with hypertension.

Methods: We conducted a cross-sectional mailed survey of patients from 2 medical centers in Minnesota. Participants with 2 or more medical conditions completed the Patient Experience with Treatment and Self-management (PETS), a validated treatment burden questionnaire, as well as measures of confidence in self-management ability, health literacy, health care-related financial difficulties, and perception of provider interpersonal skills. We used partial correlation analyses, controlling for age, sex, race, and education, to test relationships among study variables.

Results: of 254 respondents who had a diagnosis of hypertension, $54 \%$ were female, $74 \%$ were nonHispanic White, and the mean age was 67 years. People with hypertension who reported having lower confidence in self-management ability, lower health literacy, more financial difficulties, and health care providers with poorer interpersonal skills reported higher treatment burden scores (PETS scales correlation magnitude range 0.09 to $0.62, P<.05$ on all but 4 ). The strongest associations were observed for medical information and physical/mental exhaustion with self-management (correlation magnitudes from 0.25 to $0.54, P<.01$ ).

Discussion: Hypertension treatment guideline stringent blood pressure criteria may lead to more interventions - medical or lifestyle - creating strains on populations already challenged by abstract disease self-management and at risk of experiencing disparities in cardiovascular health outcomes. $(\mathrm{J}$ Am Board Fam Med 2021;34:1243-1245.)

Keywords: Cardiovascular Diseases, Chronic Disease, Cross-Sectional Studies, Disease Management, Hypertension, Minnesota, Patient-Reported Outcome Measures, Self-Management, Surveys and Questionnaires

\section{Introduction}

The 2017 US hypertension guidelines lowered blood pressure levels that define "hypertension," resulting

This article was externally peer reviewed.

Submitted 4 May 2021; revised 8 July 2021; accepted 13 July 2021.

From the Department of Medicine, University of Minnesota Medical School, Minneapolis, MN (EAR, ML); Department of Pediatrics, University of Minnesota Medical School, Minneapolis, MN (EAR, HA); Department of Medicine, Hennepin Healthcare, Minneapolis, MN (ML); Division of Health Care Delivery Research, Mayo Clinic, Rochester, MN (DTE).

Funding: DTE's work was supported by the National Institute of Nursing Research of the National Institutes of Health (NIH) under award number R21NR012984. EAR was supported through award number K23DK118207 from the NIH National Institute of Diabetes and Digestive and Kidney Diseases. HA was supported through the UMN CTSI's Pathways to Research Program (NIH NCATS award number UL1TR002494). The content is solely the responsibility of the in $63 \%$ of 45 to 75 year-olds being labeled "hypertensive." ${ }^{1}$ This will lead to more people taking multiple medications or implementing lifestyle changes,

authors and does not necessarily represent the official views of the National Institutes of Health. ML is supported in his work at Hennepin Healthcare on burnout reduction by the American Medical Association, the American College of Physicians, the American Board of Internal Medicine, and the Institute for Healthcare Improvement. He is also supported by the NIH and the Agency for Healthcare Research and Quality (AHRQ) and consults on a grant for Harvard University on clinician work conditions and diagnostic accuracy. He has received honoraria for Medical Grand Rounds from Harvard University, the University of Chicago, and Montefiore Medical Center in the past 3 years. Conflict of interests: No conflicts of interest reported.

Corresponding author: Elizabeth A. Rogers, MD, MAS, Division of General Internal Medicine, 717 Delaware Street SE, Suite 166, Minneapolis, MN 55414, Phone: 612-6240468 (E-mail: earogers@umn.edu). 
complicating self-management. ${ }^{2}$ Treatment burden -the work of self-management and its impact on function and well-being ${ }^{3}$-is associated with decreased adherence and worse health outcomes. ${ }^{4}$ Thus, the guidelines could increase disparities in hypertension control and cardiovascular outcomes in those who are already challenged by self-management. ${ }^{5}$

In this study, we assess several domains of treatment burden in people with multimorbidity, including hypertension, and attempt to identify the degree to which it is associated with factors related to self-management.

\section{Methods}

Data come from a cross-sectional survey completed by patients with multiple chronic conditions from a safety-net hospital and a large, multi-specialty practice. $^{3}$ Surveys (in English) were mailed from October to December 2014 and included the Patient Experience with Treatment and Self-management questionnaire (PETS, version 1.0), a novel measure of treatment burden composed of 48 items organized into 9 multi-item and 2 single-item scales (see Table). All scales are standardized from 0 to 100, with higher scores reflecting more burden. A description of the PETS and its validity can be found in Eton et al (2017). ${ }^{3}$ The survey also included valid measures of factors related to chronic disease self-management: ${ }^{2}$ confidence in disease self-management ability "self-efficacy", subjective health literacy, provider interpersonal skills, and health care-related financial difficulties (see Table legend for detail). Demographics and the number of prescription medications were also part of the survey. Partial correlations examined relationships between variables, controlling for demographics (age, sex, race, and education). The study was deemed exempt by both site Institutional Review Boards.

\section{Results}

Of 332 respondents (40\% response rate), 254 (77\%) had hypertension and were included (mean age $=67$ years, $54 \%$ female, $18 \%$ Black, $67 \%$ college educated).

Table 1. Partial Correlations of Treatment Burden Domains (PETS Scale Scores) with Factors Associated with Chronic Disease Self-Management in 254 People with Hypertension ${ }^{\dagger}$

\begin{tabular}{|c|c|c|c|c|c|}
\hline $\begin{array}{l}\text { Treatment Burden } \\
\text { Domains (PETS } \\
\text { scales) }^{\dagger}\end{array}$ & $\begin{array}{l}\text { Scale Scores, } \\
\text { Mean (SD) }\end{array}$ & $\begin{array}{l}\text { Self-Efficacy } \\
\text { (PMCSM scale) }\end{array}$ & $\begin{array}{l}\text { Low Health } \\
\text { Literacy" }\end{array}$ & $\begin{array}{c}\text { Financial } \\
\text { Difficulties }\end{array}$ & $\begin{array}{l}\text { Relational Quality } \\
\text { (HPRQ)\# }\end{array}$ \\
\hline Medical information & $24.7(19.2)$ & $-0.52^{* * *}$ & $0.35^{\text {*** }}$ & $0.42^{* * *}$ & $-0.54^{* * *}$ \\
\hline Medications & $9.1(16.3)$ & $-0.34^{\star * *}$ & 0.16 & $0.40^{* * *}$ & $-0.25^{* *}$ \\
\hline Medical appointments & $10.4(20.0)$ & $-0.34^{* * *}$ & $0.20^{*}$ & $0.40^{* * *}$ & $-0.35^{\star * *}$ \\
\hline Monitoring health & $16.1(23.1)$ & $-0.39^{* * *}$ & $0.17^{*}$ & $0.28^{* *}$ & $-0.27^{* *}$ \\
\hline Interpersonal challenges & $11.4(18.1)$ & $-0.39^{* * *}$ & $0.38^{* * *}$ & $0.45^{\text {*** }}$ & $-0.33^{* * *}$ \\
\hline $\begin{array}{l}\text { Medical/healthcare } \\
\text { expenses }\end{array}$ & $36.5(26.5)$ & $-0.39^{* * *}$ & $0.32^{* * *}$ & $0.52^{* * *}$ & $-0.31^{\text {*** }}$ \\
\hline $\begin{array}{l}\text { Difficulty with } \\
\text { healthcare services }\end{array}$ & $30.0(19.8)$ & $-0.34^{* * *}$ & 0.16 & $0.30^{* * *}$ & $-0.62^{* * *}$ \\
\hline $\begin{array}{l}\text { Role/social activity } \\
\text { limitations }\end{array}$ & $15.0(23.0)$ & $-0.29^{* * *}$ & $0.17^{*}$ & $0.49^{* * *}$ & $-0.22^{* *}$ \\
\hline $\begin{array}{l}\text { Physical } / \text { mental } \\
\text { exhaustion }\end{array}$ & $22.8(24.4)$ & $-0.48^{* * *}$ & $0.25^{\text {** }}$ & $0.51^{\text {*** }}$ & $-0.38^{\star * *}$ \\
\hline $\begin{array}{l}\text { Medication reliance } \\
\text { bother }\end{array}$ & $20.5(30.5)$ & $-0.29^{\star * *}$ & 0.07 & $0.41^{* * *}$ & $-0.24^{* *}$ \\
\hline $\begin{array}{l}\text { Medication side effects } \\
\text { bother }\end{array}$ & $15.9(25.3)$ & $-0.35^{* * *}$ & $0.22^{* *}$ & $0.35^{\text {*** }}$ & -0.09 \\
\hline \multicolumn{2}{|c|}{ Mean correlation across PETS domains } & -0.34 & 0.22 & 0.41 & -0.33 \\
\hline
\end{tabular}

HPRQ, Healthcare Provider Relational Quality; PETS, Patient Experience with Treatment and Self-management; PMCSM, Perceived Medical Condition Self-Management scale; SD, standard deviation.

${ }^{\dagger}$ Analyses control for the following demographic characteristics: age, sex, race, and education status.

${ }^{\ddagger}$ A higher PETS score indicates greater treatment burden, with a score range from 0 to 100 .

${ }^{\$}$ A higher PMCSM score indicates greater self-efficacy (Wallston et al., 2011).

"A higher single item literacy screener score indicates lower subjective health literacy. (Morris et al., 2006).

"A higher single item score indicates more financial difficulties due to medical treatment or physical condition (Eton et al., 2017).

${ }^{\#}$ A higher HPRQ score indicates better HPRQ (Eton et al., 2017).

${ }^{*} P<.05 ;{ }^{* *} P<.01 ;{ }^{* * *} P<.001$. 
Although $85 \%$ reported insurance coverage for most health expenses, $26 \%$ experienced at least some health care financial challenges. Low health literacy (endorsement of needing at least some help reading health care material) was reported by $17 \%$, and $66 \%$ took 4 or more prescription medications.

Treatment burden scores were highest in the medical/health care expenses $($ score $=36.5)$ and difficulty with health care services (score $=30.0$; see Table). Furthermore, as shown in the Table, lower self-efficacy, lower health literacy, more financial difficulties, and poorer provider relational quality were associated with greater treatment burden. Health care-related financial difficulties were most strongly associated with burden domains (mean correlation with PETS scales=0.41). Seven of 11 burden domains were significantly associated with all 4 of the self-management factors, with the strongest associations observed for medical information (correlation magnitudes from 0.35 to $0.54, P<.001$ ) and physi$\mathrm{cal} /$ mental exhaustion with self-management (correlation magnitudes from 0.25 to $0.51, P<.01$ ).

\section{Discussion}

People with hypertension and other chronic conditions who reported higher treatment burden expressed challenges related to chronic disease selfmanagement, including lower self-efficacy, lower health literacy, more health-related financial strain, and less patient-centered communication with providers. Intensifying self-management regimens to follow guidelines may disproportionately affect those already challenged to adhere to self-management. An unintended consequence of this guideline might then be to worsen disparities in patient experience and outcomes. How to mitigate such effects requires further research and proactive policies.
Study limitations include the use of cross-sectional, self-reported data, the inclusion of Englishspeaking participants only, and no measure of blood pressure. The correlational nature of the study precludes causal statements, and the clinical meaningfulness of PETS scores is unknown at present. Future research should consider whether addressing potentially modifiable factors might lessen treatment burden and lower the risk that hypertension treatment guidelines exacerbate health disparities.

H. Abi has changed affiliation and is no longer with the University of Minnesota.

To see this article online, please go to: http://jabfm.org/content/ 34/6/1243.full.

\section{References}

1. Khera R, Lu Y, Lu J, et al. Impact of 2017 ACC/ AHA guidelines on prevalence of hypertension and eligibility for antihypertensive treatment in United States and China: nationally representative cross sectional study. BMJ 2018;362:k2357.

2. Lorig KR, Holman HR. Self-management education: History, definition, outcomes, and mechanisms. Ann Behav Med 2003;26:1-7.

3. Eton DT, Yost KJ, Lai J, et al. Development and validation of the Patient Experience with Treatment and Self-management (PETS): a patient-reported measure of treatment burden. Qual Life Res 2017;26: 489-503.

4. Schreiner N, DiGennaro S, Harwell C, Burant C, Daly B, Douglas S. Treatment burden as a predictor of self-management adherence within the primary care population. Appl Nurs Res 2020;54:151301.

5. Osborn CY, Kripalani S, Goggins KM, Wallston KA. Financial strain is associated with medication nonadherence and worse self-rated health among cardiovascular patients. J Health Care Poor Underserved 2017;28:499-513. 